\title{
Black Soldier Fly-An Invaluable Weapon in the War for the Sustainability of the Agrarian Economy and Defense of the Environment
}

ISSN: 2637-7659

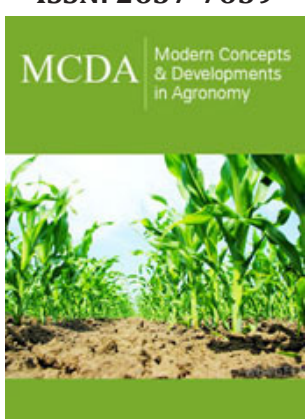

*Corresponding author: Regina Menino, Instituto Nacional de Investigação Agrária e Veterinária, IP (INIAV), Av. da República, Quinta do Marquês, 2780-159 Oeiras, Portugal

\section{Submission: 眥 March 26, 2021}

Published: 俩April 05, 2021

Volume 8 - Issue 3

How to cite this article: Regina Menino, Daniel Murta. Black Soldier Fly-An Invaluable Weapon in the War for the Sustainability of the Agrarian Economy and Defense of the Environment. Mod Concep Dev Agrono. 8(3). MCDA. 000687. 2021. DOI: 10.31031/MCDA.2021.08.000687

Copyright@ Regina Menino. This article is distributed under the terms of the Creative Commons Attribution 4.0 International License, which permits unrestricted use and redistribution provided that the original author and source are credited.

\author{
Regina Menino ${ }^{1 *}$ and Daniel Murta ${ }^{2,3,4}$ \\ ${ }^{1}$ Instituto Nacional de Investigação Agrária e Veterinária, IP (INIAV), Av. da República, Quinta \\ do Marquês, 2780-159 Oeiras, Portugal \\ ${ }^{2}$ EntoGreen-Ingredient Odyssey SA, Santarém, Portugal \\ ${ }^{3}$ CiiEM-Centro de investigação interdisciplinar Egas Moniz, Campus Universitário, Quinta da \\ Granja Monte de Caparica, 2829-511 Caparica, Portugal
}

${ }^{4}$ CIISA, Faculdade de Medicina Veterinária, Universidade de Lisboa, Lisboa, Portugal

\begin{abstract}
The growing demographic pressure, worldwide, has been alerting our planet, in an increasingly alarming way, to a progressive food deficit and a growing degradation of the quality of the environment; thus, the urgent need for new alternatives for agricultural production (among others) has been revealing the potential of insects in the two aspects mentioned above. In this context, the black soldier fly has revealed an invaluable potential for the biological composting of the remnants of agricultural production, with the triple objective of eliminating potentially polluting products, producing food for livestock farming and producing organic fertilizers capable of competing with chemical fertilizers, without the harmful effects of the latter, and with a high potential for the sustainability of the productivity of agricultural soils. The present communication, based on the advances that scientific experimentation has shown in this area, intends to highlight the high potential of this dipteran in the desideratum in question, particularly in the context of a circular economy.
\end{abstract}

\section{Introduction}

The positive feedback of scientific and technological advances (especially since the $20^{\text {th }}$ century) has provided an alarming demographic increase that is widely reported: according to FAO [1], it is predicted that by 2050 there will be an increase in the world population to nine billions.

In addition to the food shortages that persist at the global level, that perspective warns of the urgency of new solutions to tackle this problem.

The promise of the so-called "green revolution" (of the 1960s), based on the ability to create new highly productive varieties at the expense of high chemical inputs (fertilizers, phytopharmaceuticals, and fuels), was then praised for the resounding success in several countries where it was implemented, but it has been progressively revealing its perverse side, namely: in the exhaustion of fertility and in the pollution of soils and groundwater, in the reduction of water resources (by the proliferation of irrigated areas); and climate change due to the intensive use of agricultural machinery burning fossil fuels.

In this context, in this communication we intend to report on developments in one of the combat fronts (the struggle for the sustainability of the agrarian economy and defense of the environment). First, however, a brief review of the Black Soldier Fly (BSF)-the hero in this strife.

\section{Black Soldier Fly (BSF)-Curriculum vitae}

In reality, the black soldier fly (Hermetia illucens L.), from the taxonomic family Stratiomidae, is not a fly, like the one that sometimes bothers us (the Musca domestica L.) and does not even belong to the same "taxonomic" family of the Muscidae. Perhaps that is why they do not tolerate each other and are constantly struggling, with a guaranteed victory for our heroine, the BSF, who gets to eliminate 94 to $100 \%$ of the larvae of the house fly, using bird 
dung as the battlefield - as Sheppard et al. (1994) testified, in a composting experiment.

But it is not her genealogy or her hatreds that interest us here, but her diverse gifts, which lead us to bring her together in our struggle for the long-term sustainability of agrarian soils, without detriment to current productivity and with the benefit additional cost savings.

Coming from the hot and temperate regions of the New Continent, it arrived here in the middle of the last century, being immediately called to the battle, in battles that for here-in the context of this exhibition-are not necessarily called, but that reveal the diverse range of your potential.

Among these, the following stand out:

A. A very high adult prolificacy, of up to more than 600 eggs per female [3], which allows her, in just four days, to assemble an army from a platoon.

B. A pantagruelian voracity of the larvae, which allows them to devour large amounts of organic waste in a short time.

C. An ability of the larvae to accumulate food reserves in their bodies, which allows them to feed not only adults selected for reproduction, but also, together with pupae, to feed diverse animals and even humans [4].

D. A potential of the larvae, to accumulate a remarkable amount of fat in their bodies (up to $23 \%$ ), which has revealed a good potential in the production of biodiesel.

E. A proven potential of chitin present in the larvae epidermis, for the medicinal and cosmetic products industry [5];

F. And, last but not least, the fact that the larvae, in the composting process, produce high-value excreta as an organic fertilizer for a diverse range of crops.

All of this evokes his military vocation and constitutes an invaluable collection of weapons, which this "soldier", with impeccable behavior, is equipped with. If you don't believe it, notice:

A. The adults, who do not have a functional mouthpiece, feed exclusively on the abundant reserves accumulated during the larval stage and, therefore, do not harass humans and animals, thus not constituting themselves as a vector of diseases [6].

B. Their abundant stances compete with those of the house fly, thus reducing the number of larvae and adults of the latter.

C. Endowed with a high spirit of sacrifice, for the benefit of humanity, it endures the most adverse conditions on the battlefield, reaching to feed exclusively on the waste of farm animals (and not only), despite its marked preference for the remaining debris agricultural crops-in particular horticultural and fruit crops.

And if we abstain from more virtues to enunciate it is so as not to lose the reader's attention. Even so, we dare to appeal to a little more of your patience, because before entering the chapter of the strategy and tactics of war that we intend to justify in this communication, it is necessary to mention the "political" context that justifies it.

\section{"Political" context}

As mentioned in the frame outlined in the "introduction" to this communication, the dramatic problem of hunger in the world, global adulteration of the environment, and climate change are the "axis" of the belligerent triad that confronts us in the current "third world war" against the humanity.

The situation is serious, but not necessarily Armageddon, particularly if humanity is united in a global war against a powerful enemy - ironically generated by us, namely, by the following:

A. The development of industries from the "modern age", based on the consumption of fossil fuels, with the implicit objective of the profitability of companies, but capable of improving the general well-being. With this, however, it contributed to a progressive deterioration of environmental conditions and allowed an increase in demographic pressure.

B. The increase in the purchasing capacity of industrialized countries, which led to unrestrained consumerism, in positive feedback with the production of superfluous products, and the successive replacement of valid equipment, quickly made obsolete by the permanent proposal of new solutions, not always more efficient, but almost always more attractive.

C. The increase in global demographic pressure, which has led to an increase in hunger in the least technologically developed countries.

D. And so on-we could continue to list many other reasons.

And do not think that it is only the fault of the industry: with industry and commerce, services have proliferated, including transport, which is increasingly efficient, but also more polluting.

And even the primary sector is not without fault; we, those who assume the colors of the agrarian economy, also have accounts to be rendered in this registry, and we should not be exempt from our responsibilities, since:

A. Also, with the industrial revolution, we unconditionally adhere to chemical fertilizers and phytopharmaceuticals, without considering the possible consequences.

B. We often deplete, and continue to deplete, the fertility of agricultural soils, putting pressure on them to maximize yields, without considering the long-term consequences and how to avoid them.

C. We often did not know how to choose operating systems that are more in line with the environmental balance and with greater sustainability of production.

D. We have not always taken care of the proper balance between agriculture and livestock, on farms, in order to allow a greater profitability of the residues of products destined for the market-according to FAO [1], annually about $1 / 3$ of 
food produced for human consumption in the world is lost or wasted. And more could be enunciated.

But it is not worth crying over spilled milk; known the "ally" (the BSF), the "enemy" (the alliance of hunger in the world with environmental pollution and climate change), and the battlefield (agricultural and livestock farms), it remains for us to define the strategy and the tactics to use in the fight.

\section{Strategies and tactics}

The traditional strategies of agrarian companies are no longer seen as sufficient to meet the food needs of the future, nor do they safeguard the environmental resilience of the planet.

Some traditional strategies are gaining a new lease of life but do not solve the problem, such as, for example, organic agriculture, which, when properly associated with the tactics of intercropping and crop rotation, can give very positive results in the sustainability of production and the environment; however, due to their scale and production costs, they are not seen as a global solution, and should remain confined to a restricted niche (luxury or, on the contrary, subsistence).

Other alternatives have already affirmed their space, as is the case of agriculture without soil, particularly dedicated to horticulture and floriculture. It is also only solving part of the problem, although in a more realistic way than the previous one.

The strategy that we propose in this communication is much more comprehensive, not intending to compete with other economically and environmentally proven alternatives, but rather to confront the enemy on a scale compatible with the global threat of hunger that, more than threat, has been a reality for a disproportionate percentage of our human counterparts.

To this end, the present strategy is based on the following three pillars:

A. The $1^{\text {st }}$ Pillar aims at the treatment and profitability of residues from agricultural and livestock production. This is where BSF comes into combat, with the "composting" tactic, in order to promote its economic value and eliminate (or at least drastically reduce) its potential harmful effect on the environment. Expert in this tactic, its war potential is clearly superior to that of the other insects that have been tested, effecting a faster and more efficient biological degradation of organic residues, and even in comparison with that achieved with traditional composting methods and with the systems of composting. aerobic and anaerobic digestion [7]. This pillar is decisive, as the success of the following depends on it.

B. The $2^{\text {nd }}$ Pillar-following or, better, as a consequence of the 1st Pillar-consists of obtaining food for the effective animal.

C. The $3^{\text {rd }}$ Pillar aims to obtain organic fertilizers, with potential already confirmed in the immediate and deferred fertility of agricultural soil [8].

The decisive battles therefore consist of converting organic waste from animal and vegetable production into food products and organic soil fertilizers.

Food products (BSF larvae and pupae) will constitute food for poultry and/or aquaculture or, after being integrated into feed, for livestock (thus closing the cycle of animal production); organic fertilizers (excreta from the larvae in the composting process) will provide the resilience of soil productivity (thus closing the cycle of plant production).

In this context of "circular economy", productivity is maximized, and the environment is grateful, either for the conversion of pollutants into factors of production, or for drastically reducing the polluting load of soils and groundwater.

With the progressive scientific advances and the discovery of new allies, we have reason to be optimistic, but for now it is time not to underestimate allies as valuable as BSF in any of the alternatives that, to date, have considered into account the defense of the environment.

\section{Acknowledgement}

This article was performed under the scope of the NETA project: New Strategies in Wastewater Treatment (POCI-01-0247FEDER-046959) funded by PORTUGAL2020.

\section{References}

1. FAO (2013) Edible insects-Future prospects for food and feed security. Rome, Italy.

2. Sheppard DC, Newton GL, Thompson SA, Savage S (1994) A value-added manure management-system using the black soldier fly. Bioresour Technol 50(3): 275-279.

3. Tomberlin JK, Sheppard DC, Joyce JA (2002) Selected life-history traits of black soldier flies (Diptera: Stratiomyidae) reared on three artificial diets. Ann Entomol Soc Am 95(3): 379-386.

4. van Huis A, Van Itterbeeck J, Klunder H, Mertens E, Halloran A, et al. (2013) Edible insects-future prospects for food and feed security. FAO Forestry Paper 171.

5. Diener S, Zurbrügg C, Gutiérrez FR, Nguyen DH, Morel A, et al. (2011) Black soldier fly larvae for organic waste treatment- prospects and constraints; WasteSafe 2011. Proceedings of the WasteSafe 2011-2 $2^{\text {nd }}$ International Conference on Solid Waste Management in the Developing Countries, Khulna, Bangladesh, 52: 1-8.

6. Veldkamp T, van Duinkerken G, van Huis A, Lakemond CMM, Ottevanger E, et al. (2012) Insects as a sustainable feed ingredient in pig and poultry diets-a feasibility study. In: Rapport 638-Wageningen Livestock Research, Netherlands.

7. Čičková H, Newton G, Lacy R, Kozánek M (2015) The use of fly larvae for organic waste treatment. Waste Manag 35: 68-80.

8. Menino R, Felizes F, Castelo Branco MA, Fareleira P, Moreira O, et al. (2021) Agricultural value of black soldier fly larvae frass as organic fertilizer on ryegrass. Helyion 7(1): e05855. 